\title{
Weekly simulation for an on call helicopter emergency medical crew: feasible or impossible?
}

\author{
Per P Bredmose $e^{1,2^{*}}$, Stephen Sollid ${ }^{1,2}$ \\ From London Trauma Conference 2014 \\ London, UK. 9-12 December 2014
}

\section{Background}

In-situ training can be a time-effective way to give prehospital personnel an opportunity to train procedures and interventions as a team. We describe the feasibility of weekly simulation training for on-duty crews at Oslo, Norway, helicopter emergency medical service (HEMS).

\section{Methods}

HEMS crews (doctor, HEMS crew member and pilot) were given the opportunity to do in-situ simulation during on call hours once a week. A simple mannequin and training equipment similar to equipment used in daily practice in the service were used. All training took place locally, either indoors or outdoors near the base. A single facilitator conducted all training during daytime.Scenarios were changed to allow all doctors to go through a set of themes during one year, and to give variability for the rest of the crew. We recorded data on the number of simulations that were carried out and time consumption, and collected data from the participating crews on a feedback form.

\section{Results}

During one year $52 \%$ of the planned simulations were completed. The major reasons for not performing training were missions. The median total time (and interquartile range (IQR)) for a complete simulation training epiosode was $65 \mathrm{~min}(58,74)$. The median score from the participants regarding "attitude to this kind of training" was 1 on a 7 pt. Likert scale ( $1=$ most positive score possible).

\section{Discussion}

Weekly simulation provided a unique opportunity to train the whole crew in medical matters, team matters and decision-making. This form of training is cost effective because

\footnotetext{
* Correspondence: bredmose@hotmail.com

${ }^{1}$ Norwegian Air Ambulance Foundation, Drøbak, Norway

Full list of author information is available at the end of the article
}

it takes place during working hours for the on-call crew. By training on-site with familiar operational equipment the HEMS rescue man and the pilot also get handson training and familiarisation with procedures and equipment.

\section{Conclusion}

In situ simulation training during on-call hours is feasible in a busy HEMS service with no additional costs than for a facilitator.

\section{Authors' details}

${ }^{1}$ Norwegian Air Ambulance Foundation, Drøbak, Norway. ${ }^{2}$ Air Ambulance department, Prehospital Centre, Oslo University Hospital, Norway.

\section{Published: 11 September 2015}

\section{doi:10.1186/1757-7241-23-S2-A23}

Cite this article as: Bredmose and Sollid: Weekly simulation for an on call helicopter emergency medical crew: feasible or impossible? Scandinavian Journal of Trauma, Resuscitation and Emergency Medicine 2015 23(Suppl 2):A23.

Submit your next manuscript to BioMed Central and take full advantage of:

- Convenient online submission

- Thorough peer review

- No space constraints or color figure charges

- Immediate publication on acceptance

- Inclusion in PubMed, CAS, Scopus and Google Scholar

- Research which is freely available for redistribution 